\title{
BMJ Open Evaluation of a national complex oral health improvement programme: a population data linkage cohort study in Scotland
}

\author{
Jamie BR Kidd (1) , ${ }^{1}$ Alex D McMahon, ${ }^{1}$ Andrea Sherriff, ${ }^{1}$ Wendy Gnich, ${ }^{1}$ \\ Ahmed Mahmoud, ${ }^{2}$ Lorna MD Macpherson, ${ }^{1}$ David I Conway ${ }^{1}$
}

To cite: Kidd JBR, McMahon AD, Sherriff A, et al. Evaluation of a national complex oral health improvement programme: a population data linkage cohort study in Scotland. BMJ Open 2020;10:e038116. doi:10.1136/ bmjopen-2020-038116

- Prepublication history and additional material for this paper is available online. To view these files, please visit the journal online (http://dx.doi.org/10. 1136/bmjopen-2020-038116)

Received 27 February 2020 Revised 04 September 2020 Accepted 10 October 2020

\section{Check for updates}

\section{(c) Author(s) (or their} employer(s)) 2020. Re-use permitted under CC BY-NC. No commercial re-use. See rights and permissions. Published by BMJ.

${ }^{1}$ School of Medicine, Dentistry, and Nursing, University of

Glasgow, Glasgow, UK

${ }^{2}$ Public Health Scotland,

Edinburgh, UK

Correspondence to

Professor David I Conway;

david.conway@glasgow.ac.uk

\section{ABSTRACT}

Objectives Child dental caries is a global public health challenge with high prevalence and wide inequalities. A complex public health programme (Childsmile) was established. We aimed to evaluate the reach of the programme and its impact on child oral health.

Setting Education, health and community settings, Scotland-wide.

Interventions Childsmile (national oral health improvement programme) interventions: nursery-based fluoride varnish applications (FVAs) and supervised daily toothbrushing, community-based Dental Health Support Worker (DHSW) contacts and primary care dental practice visits - delivered to the population via a proportionate universal approach.

Participants 50379 children (mean age $=5.5$ years, $\mathrm{SD}=0.3)$ attending local authority schools (2014/2015).

Design Population-based individual child-level data on four Childsmile interventions linked to dental inspection survey data to form a longitudinal cohort. Logistic regression assessed intervention reach and the independent impact of each intervention on caries experience, adjusting for age, sex and area-based Scottish Index of Multiple Deprivation (SIMD).

Outcome measures Reach of the programme is defined as the percentage of children receiving each intervention at least once by SIMD fifth. Obvious dental caries experience (presence/absence) is defined as the presence of decay (into dentine), missing (extracted) due to decay or filled deciduous teeth.

Results 15032 (29.8\%) children had caries experience.

The universal interventions had high population reach: nursery toothbrushing (89.1\%), dental practice visits (70.5\%). The targeted interventions strongly favoured children from the most deprived areas: DHSW contacts (SIMD 1: $29.5 \%$ vs SIMD 5: 7.7\%), nursery FVAs (SIMD 1: $75.2 \%$ vs SIMD 5: $23.2 \%$ ). Odds of caries experience were markedly lower among children participating in nursery toothbrushing ( $>3$ years, adjusted $\mathrm{OR}(\mathrm{aOR})=0.60$; $95 \% \mathrm{Cl} 0.55$ to 0.66 ) and attending dental practice ( $\geq 6$ visits, aOR=0.55; $95 \% \mathrm{Cl} 0.50$ to 0.61 ). The findings were less clear for DHSW contacts. Nursery FVAs were not independently associated with caries experience. Conclusions The universal interventions, nursery toothbrushing and regular dental practice visits were independently and most strongly associated with reduced
Strengths and limitations of the study

- This is the first population-wide data linkage cohort study to evaluate the reach and impact of a complex public health intervention.

- There is evidence of effectiveness of oral health improvement interventions for children including fluoride toothpaste and professionally applied fluoride varnish; however, the evidence of combining these into a complex oral health improvement programme delivered via a proportionate universal approach has not previously been evaluated.

- The study uses routine administrative data, which have some limitations in the variables available, including a lack of information on intermediate individual behaviours.

- The outcome data available, the presence or absence of obvious dental caries experience, collected by trained and standardised dental inspection teams and available at the population level show a high level of agreement with detailed decay, missing, and filled teeth (dmft) index scores collected by calibrated dental inspection teams on a much smaller sample of children.

- The study strengths are in the robust data linkage approach, where there were no concerns about the quality and completeness of the data linkage, resulting in a cohort with population-wide coverage of outcome and intervention data.

odds of caries experience in the cohort, with nursery toothbrushing having the greatest impact among children in areas of high deprivation.

\section{INTRODUCTION}

Oral health is a global public health challenge with oral diseases estimated to be the most prevalent condition in the world. ${ }^{1}$ Untreated dental caries (tooth decay) of the deciduous teeth affects $8 \%$ of the global child population, with greatest prevalence in those under 5 years of age. ${ }^{2}$ In Scotland, at the beginning of the 21st century, dental caries in 5 year olds 
was among the worst in Europe, with $60 \%$ affected, wide inequalities identified and no improvement observed in the previous decade. ${ }^{3}$

A 2002 Scottish Government consultation resulted in fluoridation of the public water supply being ruled out, ${ }^{45}$ but with a realisation that a traditional health education approach for oral health improvement was both ineffective and could potentially widen inequalities. ${ }^{6}$ The resultant national oral health strategy established demonstration pilot projects which developed into the national child oral health improvement programme-Childsmile. ${ }^{7}$ The Childsmile programme is described in detail elsewhere ${ }^{8}$-briefly, it is a multicomponent preventive programme operating at upstream (policy), midstream (community) and downstream (clinical) levels. It follows a proportionate universal approach-delivering both universal interventions to all children and additional targeted interventions focused on children predicted to be at higher risk of dental caries from the most socioeconomically deprived backgrounds, with the twin aims of improving child oral health and reducing associated inequalities in the population. ${ }^{910}$ Childsmile's main focus has been on preschool children (aged up to 5 years). The four main interventions of the programme for this age group are (1) dental health support worker (DHSW) home and community contacts (targeted from birth to children and their parents/carers in greatest need as identified by health visitors, for prevention advice, to help facilitate attendance in primary care dental practice, and to link families with community assets); (2) nursery (kindergarten) fluoride varnish applications (FVAs) (targeted to children from the of age 3 years from the more deprived communities, applied twice per year by extended duty dental nurses); (3) primary care dental practice visits (available from birth for all children attending where toothbrushing instruction, diet advice and FVAs are offered); and (4) nursery-supervised toothbrushing (universal to all preschool establishments in Scotland, including daily toothbrushing with fluoride toothpaste and distribution of toothbrush/toothpaste packs for home use). Following piloting, these interventions were collectively rolled out nationally from 2010/2011.

A monitoring and evaluation strategy for the Childsmile programme was developed based on recommended approaches for the evaluation of complex interventions. ${ }^{11}$ A theory-based approach to evaluation, incorporating a logic model, guided the development of studies to gather process and outcome measures. The evaluation plan included an ecological evaluation of nursery-supervised toothbrushing, ${ }^{12} 13$ an embedded randomised controlled trial of nursery fluoride varnish ${ }^{14}$ and an individual childlevel data linkage study using the emerging NHS Scotland infrastructure (this present study). ${ }^{15}$

Several Cochrane reviews show effectiveness of the fluoride-based interventions ${ }^{16}{ }^{17}$; however, the evidence in relation to the proportionate universal delivery of combinations of these interventions at the population level is untested. Here, we developed a cohort using data linkage methods of routine administrative data to assess the reach of the Childsmile programme (with its universal and targeted interventions) by area-based socioeconomic deprivation and to undertake an analysis of the impact of the Childsmile interventions on dental caries outcomes among Primary 1 children (age range 4-6years old) in 2014/2015 in Scotland (the first cohort of children to be born into the nationally rolled-out programme) by the overall population and then by area-based socioeconomic deprivation.

\section{METHODS}

\section{Information governance approval}

Information Governance approval was granted by the NHS Scotland Public Benefit and Privacy Panel for Health and Social Care.

\section{Patient and public involvement}

Patients were not involved in the design, analyses and interpretation of this study.

\section{Databases}

Individual child-level data were linked from five databases held by NHS National Services Scotland (NSS) [now Public Health Scotland]: (1) Childsmile Dental Health Support Worker (DHSW) database ${ }^{18}$ - held information on DHSW contacts with families; (2) Childsmile Nursery Fluoride Varnish database ${ }^{18}$ - had information on nursery FVAs; (3) Management Information and Dental Accounting System (MIDAS) ${ }^{19}$ —collated information on all child and adult primary care dental practice appointments and treatments in Scotland (including Childsmile practice prevention items); (4) Childsmile Nursery Toothbrushing database ${ }^{18}$ - collected information on parent/carer consent indicating child-level participation in the nursery-supervised toothbrushing programme; and (5) National Dental Inspection Programme (NDIP) database $^{20}$ - which included an annual survey of oral health outcomes on all Primary 1 (P1) school-year (approximately 5 years old) children attending local authority schools. The dental inspection involved a simple assessment of the mouth and teeth of each child undertaken by trained and standardised primary care dental teams within primary schools. Dental caries experience of the deciduous dentition was recorded. ${ }^{20}$ The child's sex was ascertained from the NDIP database and age at inspection derived. In addition, the area-based Scottish Index of Multiple Deprivation 2009 (SIMD) ${ }^{21}$ level was linked to the child's home postcode at the time of their dental inspection.

\section{Cohort inclusion criteria}

Our longitudinal cohort included all children in P1 at local authority schools in the 2014/2015 school year (July 2014-June 2015) who underwent an NDIP dental inspection and were aged between 4 and 6 years of age and whose 


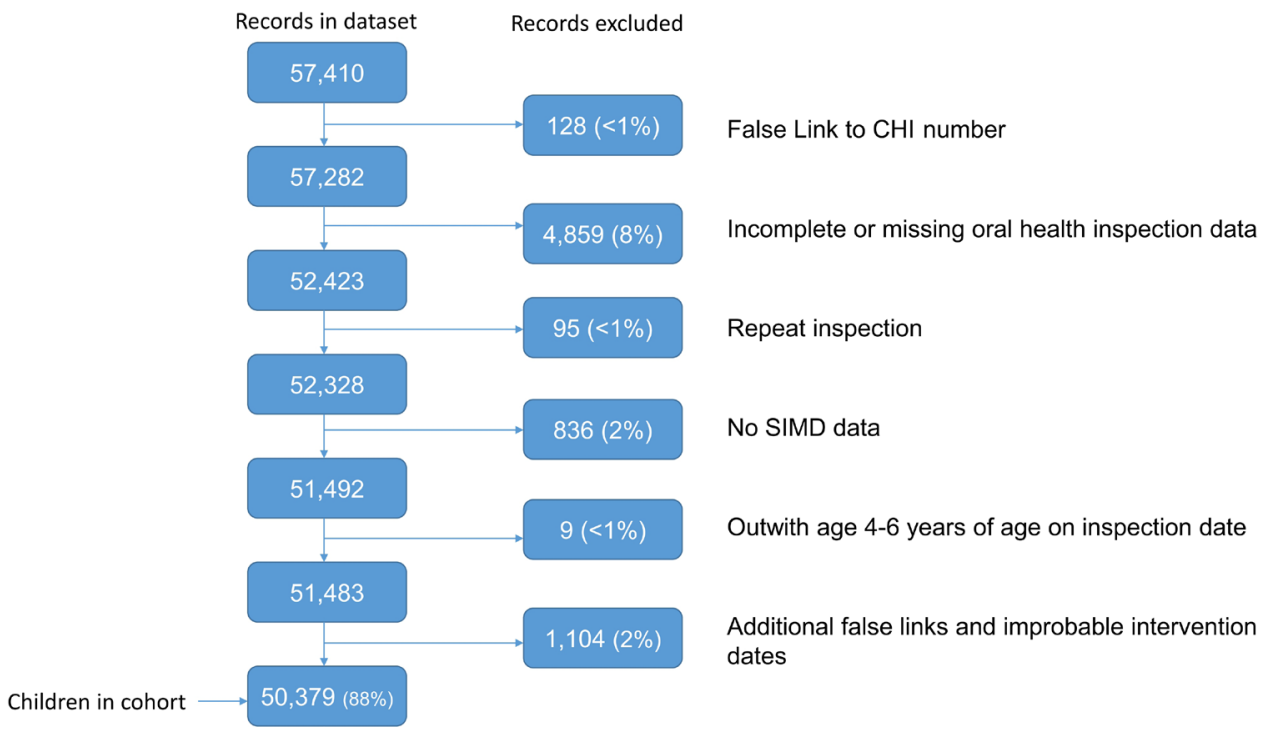

Figure 1 Flow chart of records excluded from the 2014/2015 P1 National Dental Inspection Programme (NDIP). CHI, Community Health Index; SIMD, Scottish Index of Multiple Deprivation.

record could be reliably linked across datasets. Details of the linkage procedure can be found elsewhere. ${ }^{22}$ This cohort was initially seeded via probability matching ${ }^{23}$ with the Community Health Index (CHI) which is NHS Scotland's unique patient identifier number. As the CHI number is held on all the other national level health datasets in NSS, we then linked the children in our cohort to their corresponding records in the Childsmile intervention datasets.

\section{Data management}

Prior to obtaining the datasets for our study, NSS removed the personal identifiable variables (CHI number, forename, surname and home postcode) from the datasets. The CHI numbers were replaced with study-specific pseudo anonymised IDs that allowed all the records belonging to an individual across all the datasets to be linked without the need for personal identifiers.

We undertook a series of data cleaning procedures and excluded NDIP records for a variety of reasons (figure 1). To assess data completeness and linkage success, where possible, the total number of children in the linked cohort receiving each intervention type and the outcome of their NDIP inspection were compared with appropriate published reports which had been based on single databases. ${ }^{24} 25$

The vast majority of the 52579 children that received a dental inspection in 2014/2015 were in the linked cohort $(\mathrm{n}=52386,99.6 \%)$. During the NDIP data cleaning process, exclusions were minimal, but there were more children excluded with no inspection from the most deprived areas SIMD $1(\mathrm{n}=1358 ; 10.1 \%)$ than from the least deprived areas SIMD $5(\mathrm{n}=615 ; 6.3 \%)^{22}$; however, the incidence of dental caries within the cohort remained representative of the population. ${ }^{25}$

\section{Outcome and intervention data definitions}

The reach of each of the programme interventions was measured descriptively by the proportion of the child population receiving each intervention on at least one occasion or having consented to nursery-supervised toothbrushing by SIMD deprivation fifth.

The impact of the interventions on dental caries (defined as 'caries experience' throughout) was measured by the presence or absence of obvious caries experience which was determined clinically by the presence of decay (caries into dentine), missing (extracted due to decay) or filled deciduous teeth-following recognised criteria, ${ }^{26}$ although due to the nature of the basic NDIP dental inspection being undertaken (rather than a detailed epidemiological assessment) a $\mathrm{dmft}$ score was not available. This outcome measure was available in all children in the cohort for the school year 2014/2015 from the NDIP database. ${ }^{25}$ SIMD was categorised as fifths, with SIMD 1 representing the $20 \%$ most deprived areas and SIMD 5 the $20 \%$ least deprived areas.

We derived appropriate categories for each of the four Childsmile interventions. The number of times (from birth to outcome) a targeted family received a DHSW contact (DHSW Contacts), the number of times a targeted child received a nursery FVA between the age of 3 years and outcome (Number of Nursery FVA), and the number of Primary Care Dental Practice Visits interventions a child received between birth and the outcome were calculated. Children in the cohort who were not enrolled at a nursery targeted for the FVA intervention or were not identified by a health visitor as requiring a DHSW Contact were categorised as 'Not targeted' for these interventions. Nursery-Supervised Toothbrushing participation was captured using the parent/carer annual consent forms-categorised as the number of years the 
child was consented to participate in toothbrushing prior to the cohort outcome endpoint.

\section{Statistical analyses}

Programme reach

Differences in the reach (gradient across SIMD groups) of each intervention by area-based deprivation (SIMD) were tested using logistic regression of reach with SIMD fifths treated as a continuous variable. This provides the OR for 'reach' according to a one-unit change in the SIMD indicating whether there was a significant increasing or decreasing trend in those children with at least one dose of a component across the deprivation groups.

\section{Caries experience}

Logistic regression was used throughout to model the binary endpoint caries experience and a series of steps were taken in the modelling process. In the first instance, unadjusted ORs and 95\% CIs for caries experience were calculated for each potential confounder available in the datasets (age, sex, SIMD) and each of the four interventions individually. A main effects analysis was then conducted to establish the associations between each of the four Childsmile interventions (individually) and caries experience adjusting only for the confounders (Model 1). Model 2 then assessed the independent effects of each intervention, adjusted for the confounders and all other interventions. In addition, interaction terms were added to the models to test whether the impact of the interventions on caries experience were modified by the confounders (ie, were any of the interventions having a greater impact in particular groups). Where statistically significant $(p<0.05)$ interactions were observed, the results of Model 1 and Model 2 were partitioned by the interacting variable.
This work was undertaken within NHS Scotland's National Safe Haven ${ }^{27}$ and reported following best practice guidance. ${ }^{28} 29$ All statistical analyses were undertaken using SAS Enterprise Guide V.5.1 (SAS Institute).

\section{RESULTS}

The cohort included 50379 children $84.7 \%$ of the 5 -year-old population estimate in 2015) with an outcome measure of caries experience (yes/no) from the NDIP dental inspection data (2014/2015), of which $29.8 \%$ $(\mathrm{n}=15032)$ had caries experience (table 1$)$. The distribution of caries experience by both the potential confounders and the exposure levels of each Childsmile intervention are reported in online supplemental table 1. The majority $(n=43165,85.7 \%)$ of children in the cohort were 5 years old (mean age $=5.5, \mathrm{SD}=0.3$ ), and as expected, caries experience increased with age: from $26.5 \%(\mathrm{n}=788)$ in 4 year olds to $32.9 \%(\mathrm{n}=1397)$ among 6 year olds. Of the cohort, $50.9 \%(\mathrm{n}=25643)$ were males with caries experience slightly higher among this group $(\mathrm{n}=7903,30.8 \%)$ in comparison with females $(\mathrm{n}=7129$, $28.8 \%$ ). The odds of caries experience in children living in the most deprived areas (SIMD 1) was more than four times greater than those living in the least deprived areas $(\mathrm{SIMD} 5)(\mathrm{OR}=4.39,95 \%$ CI $4.10,4.70)$.

\section{Reach of the programme according to area-based deprivation} The percentage of children in the cohort reached by each of the four interventions according to SIMD fifth is presented in figure 2 and the ORs (95\% CI) for reach (gradient) of each intervention by SIMD are presented in online supplemental table 2. Of the cohort, $17.4 \%$ $(\mathrm{n}=8753)$ were reached by the (targeted) DHSW contacts

Table 1 Unadjusted and adjusted ORs and 95\% Cls for caries experience according to potential confounders

\begin{tabular}{|c|c|c|c|c|c|}
\hline & $\begin{array}{l}\text { Total number of } \\
\text { children in cohort }\end{array}$ & $\begin{array}{l}\text { Caries } \\
\text { experience }\end{array}$ & OR & $95 \% \mathrm{Cl}$ & $P$ value \\
\hline & $n=50379$ & $\mathrm{n}=15032(29.8 \%)$ & & & \\
\hline \multicolumn{6}{|l|}{ SIMD } \\
\hline 1 (most deprived) & 11777 & $5310(45.1)$ & 4.39 & (4.10 to 4.70 ) & $<0.001$ \\
\hline 2 & 10092 & 3549 (35.2) & 2.90 & (2.70 to 3.11 ) & $<0.001$ \\
\hline 3 & 9609 & $2597(27.0)$ & 1.98 & (1.84 to 2.13 ) & $<0.001$ \\
\hline 4 & 9876 & $2154(21.8)$ & 1.49 & (1.38 to 1.61$)$ & $<0.001$ \\
\hline 5 (least deprived) & 9025 & $1422(15.8)$ & - & Referent & - \\
\hline \multicolumn{6}{|l|}{ Age } \\
\hline 4 & 2974 & 788 (26.5) & 0.85 & (0.78 to 0.93 ) & $<0.001$ \\
\hline 5 & 43165 & $12847(29.8)$ & - & Referent & - \\
\hline 6 & 4240 & $1397(32.9)$ & 1.16 & (1.08 to 1.24$)$ & $<0.001$ \\
\hline \multicolumn{6}{|l|}{ Sex } \\
\hline Female & 24736 & 7129 (28.8) & 0.91 & (0.87 to 0.94$)$ & $<0.001$ \\
\hline Male & 25643 & 7903 (30.8) & - & Referent & - \\
\hline
\end{tabular}

SIMD, Scottish Index of Multiple Deprivation Index. 


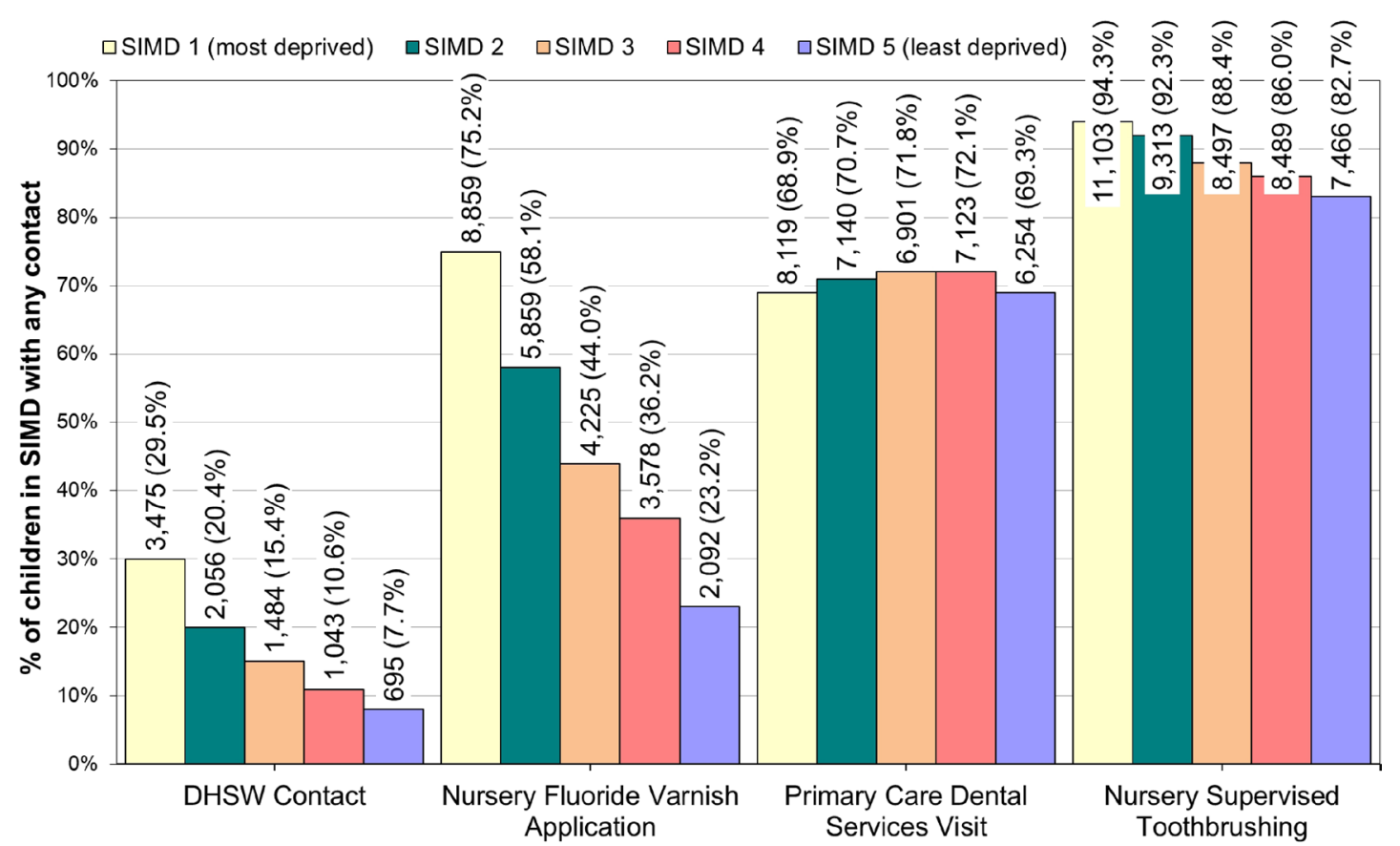

Figure 2 Number and percentage of children in each SIMD category reached by each Childsmile intervention in cohort. DHSW, Dental Health Support Worker; SIMD, Scottish Index of Multiple Deprivation.

intervention with a strong decreasing trend across the SIMD distribution (most to least deprived) (OR for slope $=0.67 ; 95 \%$ CI 0.65 to 0.68$)$. Almost one-third $(\mathrm{n}=3475 / 11777,29.5 \%)$ of those children living in the $20 \%$ most deprived areas received a DHSW contact in contrast to just under one-tenth $(\mathrm{n}=695 / 9025,7.7 \%)$ in the least deprived areas. Similarly, for the (targeted) nursery FVA intervention, where $48.9 \%$ of the cohort $(\mathrm{n}=24613)$ had at least one nursery FVA in the study period, a strong decreasing trend in reach was observed across the SIMD distribution (most to least deprived) (OR for slope $=0.58 ; 95 \%$ CI $0.57,0.58)$. Three-quarters $(\mathrm{n}=8859,75.2 \%)$ of those living in the $20 \%$ most deprived areas received at least one nursery FVA, compared with 23.2\% $(n=2092)$ in the least deprived areas.

Within the cohort ( $\mathrm{n}=35537), 70.5 \%$ of children had a (universal) primary care dental practice visit, with a flat gradient across the SIMD distribution (OR for slope $=1.01$; $95 \%$ CI 1.00 to 1.03 ) with only a very small absolute difference between least and most deprived fifths: $0.4 \%$ (SIMD 1: $\mathrm{n}=8119,68.9 \%$ vs SIMD 5: $\mathrm{n}=6254,69.3 \%$ ). There was a high level of reach across the population for the (universal) nursery-supervised toothbrushing intervention $(89.1 \% \mathrm{n}=44868)$. The decreasing trend by SIMD was considerably weaker (OR for slope $=0.75 ; 95 \% 0.73$ to 0.77 ), and the absolute difference between most and least deprived fifths of SIMD was much smaller (SIMD 1: $\mathrm{n}=11103,94.3 \%$ to SIMD 5: $\mathrm{n}=7466,82.7 \%$ ) than for the targeted interventions.

\section{Impact of the interventions on caries experience}

The associations between each of the interventions and caries experience are presented in table 2. The main results, adjusted for confounders (age, sex, SIMD) and all other interventions, are described here (Model 2). The results of Model 1 (adjusted for confounders only) are presented in the tables for comparison purposes.

\section{DHSW contacts intervention}

Relative to those targeted and not reached for a DHSW contact, children receiving only one contact had $31 \%$ lower odds of caries experience (aOR $=0.69 ; 95 \%$ CI 0.60 to 0.80 ); however, there was insufficient evidence for an association with two or more contacts ( $\mathrm{aOR}=0.95 ; 95 \%$ CI 0.79 to 1.15 ). This effect of DHSW contacts on caries experience after the Model 2 adjustment had attenuated slightly from Model 1 but did not change the overall results.

\section{Nursery FVA intervention}

Children targeted for nursery FVAs, in comparison to children receiving zero applications, had no reduction in the odds of caries experience regardless of the number applied (five applications, aOR=0.97; 95\% CI 0.89 to 1.06). This effect of Model 2 had attenuated in comparison to Model 1.

\section{Primary care dental practice intervention}

The odds of caries experience reduced as the number of primary care dental practice visits increased from three (Model 2). Those attending $\geq 6$ times experienced, on average, a $45 \%$ reduced odds of caries experience (aOR $=0.55 ; 95 \%$ CI 0.50 to 0.61$)$, compared with those who never attended. There was very little change in the effect of the primary care dental practice visits in comparison to those observed for Model 1.

Nursery-supervised toothbrushing intervention

Compared with those who did not participate in the nursery-supervised toothbrushing intervention (Model 


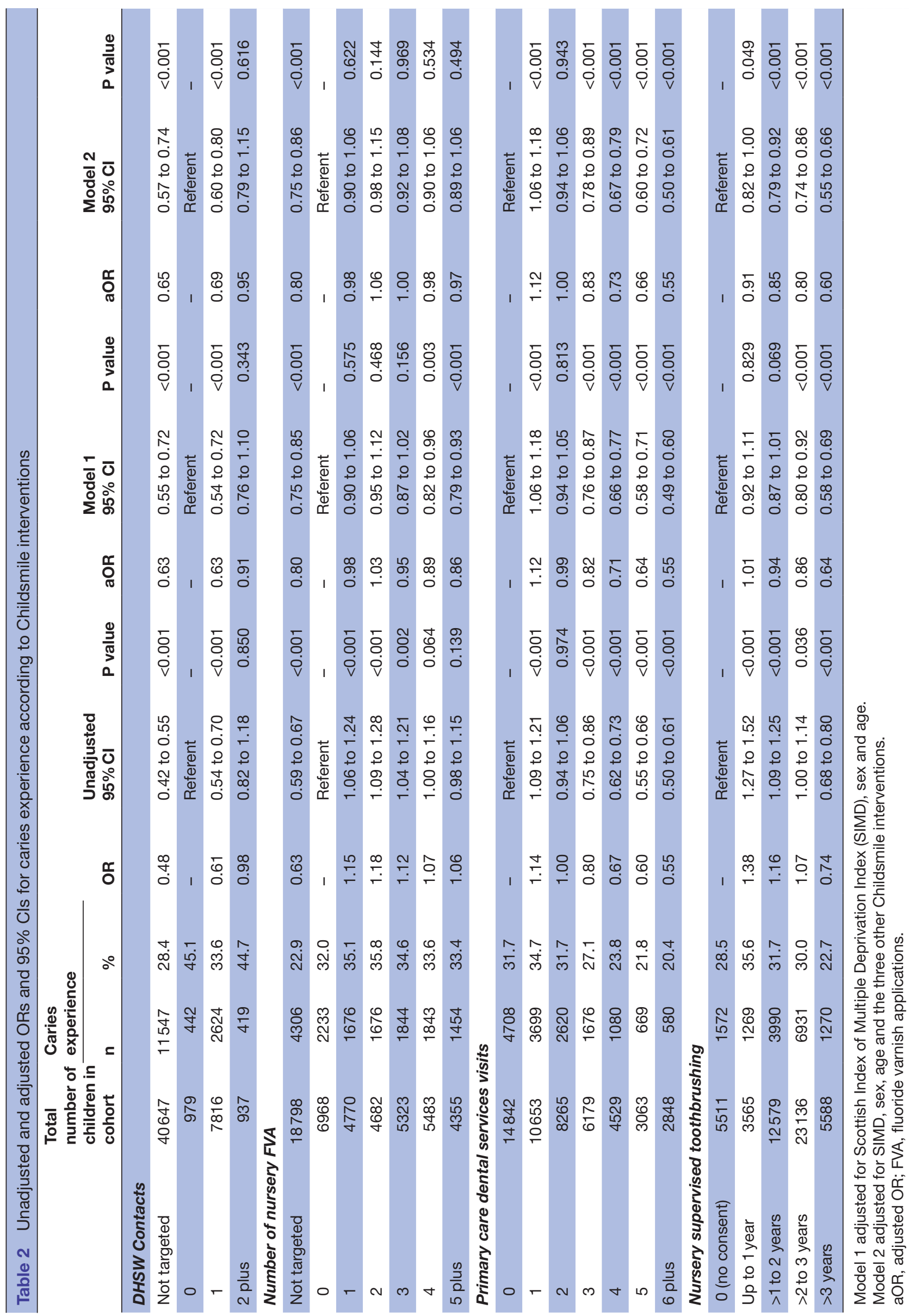



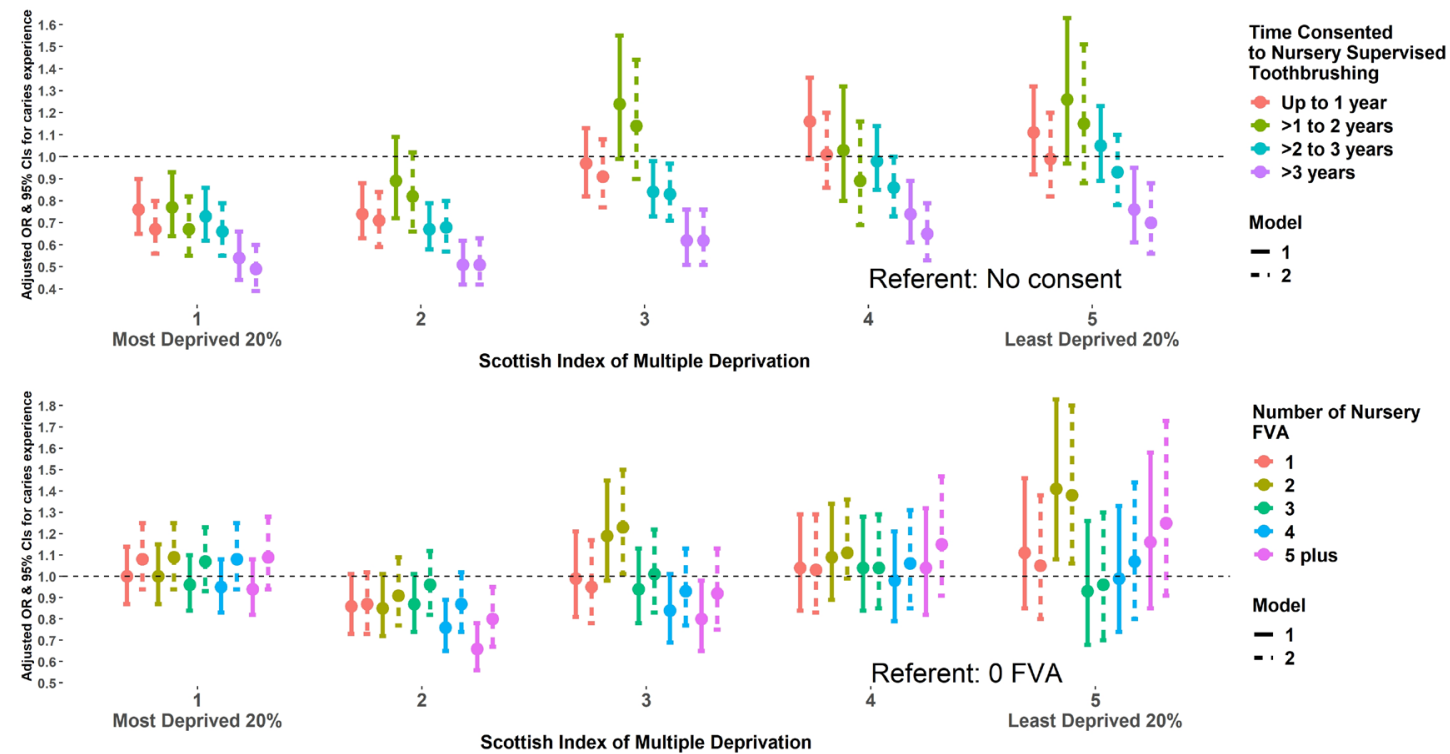

Figure 3 Unadjusted and adjusted ORs and 95\% Cls for caries experience according to nursery-supervised toothbrushing and nursery fluoride varnish applications (FVAs) by SIMD. Model 1 adjusted for Scottish Index of Multiple Deprivation Index (SIMD), sex and age. Model 2 adjusted for sex, age and the three other Childsmile Interventions.

2), there was a reduction in the odds of caries experience as the number of years of participation increased with those participating for ' $>3$ years' relative to not consented having substantial reduced odds of caries experience (aOR $=0.60 ; 95 \%$ CI 0.55 to 0.66 ). This effect was slightly strengthened in comparison to Model 1.

There were no significant interactions observed with age or sex and all four interventions on caries experience, nor with SIMD and DHSW contacts or primary care dental practice visits. Figure 3 depicts that the impact of the nursery-supervised toothbrushing intervention on caries experience was modified by SIMD $(\mathrm{p}<0.001)$, with the odds of caries experience lower for those in SIMD 1 (Model 2) who participated in this intervention for $>3$ years $(\mathrm{aOR}=0.49 ; 95 \% \mathrm{CI} 0.39$ to 0.60 vs those with no consent) in contrast to those in SIMD 5 who participated for the same amount of time (aOR=0.70; $95 \%$ CI 0.56 to 0.88 vs those with no consent) (see online supplemental table 3 ).

There was also an interaction between SIMD and nursery FVA on caries experience $(p=0.014)$, although it was weaker than that observed for SIMD and nurserysupervised toothbrushing (figure 3). A reduction in the odds of caries experience was only observed for children living in SIMD 2 (Model 2) after receiving five or more varnishes $(\mathrm{aOR}=0.80 ; 95 \% \mathrm{CI} 0.67$ to 0.95 ) (see online supplemental table 4$)$.

\section{DISCUSSION}

We have demonstrated that it was possible to create a study cohort via data linkage of routine administrative datasets, and to undertake an initial evaluation of a complex public health intervention.

The four Childsmile interventions examined here are largely being delivered as envisaged in the Childsmile strategy $^{30}{ }^{31}$ with respect to their differing targeted and universal aims. This demonstrates a good example of proportionate universalism, where the intensity of interventions across the socioeconomic gradient is proportionate to need. There was near universal coverage observed for the nursery-supervised toothbrushing intervention in keeping with findings that nearly all the nurseries nationally (establishment level) in 2015 were participating in the programme. ${ }^{24}$ There were no socioeconomic inequalities observed with the reach of the primary care dental practice intervention which may in part be explained by findings that DHSWs were effective at getting targeted children from more deprived areas into a dental practice earlier than expected. ${ }^{32}$ The Childsmile programme health boards implemented the level of targeting in the fluoride varnish intervention in nurseries in slightly different ways. ${ }^{24}$ It was therefore important, at the national population level, to assess the proportion reached across the SIMD distribution, as well as focusing on the most deprived areas. Targeting of the DHSW intervention was often determined on a judgement made by a health visitor based on an individual family's need. Therefore, there could be children/families targeted that did not live in areas of high deprivation. Nevertheless, there was an expectation that there should be a general trend in reach of the DHSW intervention towards reaching children from the more deprived areas. However, with only $30 \%$ of children from the most deprived areas receiving the DHSW intervention, there is room for improving the targeting approach in the programme.

Overall, nursery-supervised toothbrushing, dental practice visits and (to a lesser degree) DHSW contacts were all independently associated with a reduction in caries experience, but there was insufficient evidence for an independent association of the nursery FVA intervention with 
caries experience. The nursery-supervised toothbrushing intervention appeared to have the greatest impact in children from the $40 \%$ most deprived areas.

These results support findings from our earlier ecological study that suggested that Childsmile nurserysupervised toothbrushing was driving the reduction in the population trends of dental caries. ${ }^{12}$ Our results provide new evidence to support the impact of nurserysupervised toothbrushing in reducing risk associated with caries experience, with it being strongest for children from the most deprived communities where it was also apparent with only 1 year of participation. Children living in the $40 \%$ least deprived areas only had a significant reduction in odds of caries experience after more than 3 years of participation when compared with their nonparticipating peers. One possible explanation for this is that children living in the most affluent areas are more likely to already be regularly toothbrushing at home ${ }^{33} 34$ and as a result may have been at a lower risk of caries experience to begin with. Children who were regular attenders at Childsmile dental practices had significantly less caries experience than irregular or non-attenders and this did not differ by area-based socioeconomic level as observed in other studies. ${ }^{35}{ }^{36}$ Regular dental attendance is also associated with other oral health behaviours such as good oral hygiene and diet. ${ }^{35}{ }^{37}$ In this study, frequent dental attendance seems to be a marker for better oral health and could be associated with motivated, enabled and health conscious parents/carers, rather than being genuinely causal in reducing caries risk. The alternative explanation that regular dental attendance could also have a role to play in ensuring that children have no dental caries (through their delivery of preventive interventions) cannot be ruled out. However, the limited evidence of effectiveness of chairside advice-based interventions casts some doubt on the role of dental teams in driving oral health improvement, for example, there remains limited trial or systematic review evidence on the preventive effect of diet or toothbrushing advice, ${ }^{37}$ and even the effectiveness of practice-delivered FVAs is being questioned. ${ }^{38}$ Furthermore, there was very little evidence that FVAs within the nursery setting reduced odds of caries experience after adjustment for the other three interventions. Although systematic reviews of fluoride varnish show a clear caries preventive effect in children, ${ }^{16}$ a more recent review is beginning to cast doubt over fluoride varnish effectiveness and cost-effectiveness. ${ }^{39}$ As the impact attenuated following adjustment with the other interventions, it is plausible that there was little to no benefit for receiving fluoride varnish over and above the almost universal coverage and caries preventive impact of nursery-supervised toothbrushing, or the other interventions, particularly for those living in the most deprived fifth. Our previous work has demonstrated the initial success of DHSWs in increasing earlier dental practice attendance in children from more deprived areas. ${ }^{32}$ However, the findings of this study are more difficult to interpret. A single contact conferred a reduced odds of caries experience; two or more had little impact. This could be due to DHSWs correctly identifying the most vulnerable families in terms of needing more intensive support (more contacts), but their efforts being unable to mitigate and reduce the odds of dental caries by 5 years of age.

To our knowledge, this was the first population-level cohort study to evaluate a complex public health intervention using routine administrative data. There have been several studies to date examining epidemiological questions or the impact of single interventions (eg, medications).$^{40}$ Internationally, there have been many developments in data linkage cohorts for longitudinal follow-up, disease surveillance, service evaluation or policy modelling purposes. ${ }^{41} 42$ Our study used routine administrative databases, the limitations of which are recognised ${ }^{43}$ as they are established for other purposes, and therefore the variables available are more limited. These are more than offset by the large population coverage, and in our case because all the datasets had robust quality and completeness procedures. The NDIP basic inspection data had good population coverage providing presence or absence of caries experience collected by trained and standardised examiners, this has less detail than detailed epidemiological inspection data which includes dmft scores collected by calibrated examiners-although these data would only be available on a small sample (20\%) of children. The NDIP reports show high level of agreement between the basic and detailed inspection caries prevalence data. ${ }^{20}$ Moreover, the linkage process with intervention datasets was robust with a high linkage rate, which did not exclude many records from those expected in published reports providing a cohort representative of the population. ${ }^{25}$

\section{CONCLUSIONS}

In this first population-wide data linkage cohort study to evaluate the reach and impact of a complex public health intervention, we found that the Childsmile programme was delivered largely as envisaged in terms of targeted and universal elements across the population. The universal interventions of nursery-supervised toothbrushing (for $>3$ years) and primary care dental visits (when at a high frequency $n \geq 6$ ) were independently and most strongly associated with reducing the odds of dental caries in the child population. Nursery-supervised toothbrushing had the greatest impact among children in areas of high deprivation. These findings should inform the development of new strategies for improving population child oral health.

\section{Twitter David I Conway @davidiconway}

Acknowledgements The study formed part of a PhD thesis undertaken by JBRK in University of Glasgow, published in 2019. Forrest plots were generated by Ryan Stewart. Carole Morris, John Nolan, Katrina Smith, Dave Bailey and Shifa Sarica from Electronic Data Research and Innovation Service (eDRIS) in NHS Information Services Division (ISD) [now Public Health Scotland] assisted this study.

Contributors DIC and LMDM conceived this study. JBRK, ADM, AS, WG, AM, LMDM and DIC all contributed to the study design. JBRK with AM undertook data 
management. JBRK with ADM and AS conducted the statistical analysis. JBRK and DIC initially drafted the manuscript. All authors contributed to subsequent drafts and approved the final version.

Funding This work was supported by the Scottish Government as part of their funding of the evaluation programme of the Childsmile programme (Scottish Government Health Directorate-Evaluation of National Oral Health Improvement Programmes-2013-2016, 2016-2019).

Competing interests None declared.

Patient consent for publication Not required.

Ethics approval Ethical approval was obtained from the University of Glasgow Ethics Committee (Project number MVLS200150076).

Provenance and peer review Not commissioned; externally peer reviewed.

Supplemental material This content has been supplied by the author(s). It has not been vetted by BMJ Publishing Group Limited (BMJ) and may not have been peer-reviewed. Any opinions or recommendations discussed are solely those of the author(s) and are not endorsed by BMJ. BMJ disclaims all liability and responsibility arising from any reliance placed on the content. Where the content includes any translated material, BMJ does not warrant the accuracy and reliability of the translations (including but not limited to local regulations, clinical guidelines, terminology, drug names and drug dosages), and is not responsible for any error and/or omissions arising from translation and adaptation or otherwise.

Open access This is an open access article distributed in accordance with the Creative Commons Attribution Non Commercial (CC BY-NC 4.0) license, which permits others to distribute, remix, adapt, build upon this work non-commercially, and license their derivative works on different terms, provided the original work is properly cited, appropriate credit is given, any changes made indicated, and the use is non-commercial. See: http://creativecommons.org/licenses/by-nc/4.0/.

ORCID iD

Jamie BR Kidd http://orcid.org/0000-0003-2932-0799

\section{REFERENCES}

1 Peres MA, Macpherson LMD, Weyant RJ, et al. Oral diseases: a global public health challenge. Lancet 2019;394:249-60.

2 Kassebaum NJ, Smith AGC, Bernabé E, et al. Global, regional, and national prevalence, incidence, and Disability-Adjusted life years for oral conditions for 195 countries, 1990-2015: a systematic analysis for the global burden of diseases, injuries, and risk factors. J Dent Res 2017;96:380-7.

3 Scottish Dental Epidemiological Co-ordinating Committee. Scotland's National Dental Inspections Programme, 2003. Available: https://ndip.scottishdental.org/wp-content/uploads/2014/08/ndip_ scotland2003.pdf [Accessed 01 Nov 2020].

4 Scottish Executive. Towards Better Oral Health in Children - A Consultation Document on Children's Oral Health in Scotland, 2002. Available: https://www.webarchive.org.uk/wayback/archive/ 20180517060905/http://www.gov.scot/Publications/2002/09/15477/ 11087 [Accessed 01 Nov 2020].

5 Scottish Executive Health Department. Towards Better Oral Health in Children - Analysis of Consultation Responses, 2005

6 Schou L, Wight C. Does dental health education affect inequalities in dental health? Community Dent Health 1994;11:97-100.

7 Scottish Executive. An action plan improving oral health and modernising NHS dental services in Scoltand, 2005. Available: https://www.gov.scot/publications/action-plan-improving-oralhealth-modernising-nhs-dental-services-scotland/ [Accessed 01 Nov 2020].

8 Macpherson LMD, Ball GE, King P, et al. CHILDSMILE: the CHILD oral health improvement programme in Scotland. Prim Dent $J$ 2015;4:33-7.

9 Marmot M. Fair Society, healthy lives: the Marmot review, 2010. Available: http://www.instituteofhealthequity.org/resources-reports/ fair-society-healthy-lives-the-marmot-review/fair-society-healthylives-full-report-pdf.pdf [Accessed 01 Nov 2020].

10 Shaw D, Macpherson L, Conway D. Tackling socially determined dental inequalities: ethical aspects of Childsmile, the National child oral health demonstration programme in Scotland. Bioethics 2009;23:131-9.

11 Craig P, Dieppe P, Macintyre S, et al. Developing and evaluating complex interventions: the new medical Research Council guidance. Int J Nurs Stud 2013;50:587-92.
12 Macpherson LMD, Anopa Y, Conway DI, et al. National supervised toothbrushing program and dental decay in Scotland. J Dent Res 2013;92:109-13.

13 Anopa Y, McMahon AD, Conway DI, et al. Improving child oral health: cost analysis of a national nursery toothbrushing programme. PLoS One 2015;10:e0136211.

14 Wright W, Turner S, Anopa Y, et al. Comparison of the cariesprotective effect of fluoride varnish with treatment as usual in nursery school attendees receiving preventive oral health support through the Childsmile oral health improvement programme - the Protecting Teeth@3 Study: a randomised controlled trial. BMC Oral Health 2015:15:160.

15 Pavis S, Morris AD. Unleashing the power of administrative health data: the Scottish model. Public Health Res Pract 2015;25:e2541541.

16 Marinho VCC, Worthington HV, Walsh T, et al. Fluoride varnishes for preventing dental caries in children and adolescents. Cochrane Database Syst Rev 2013;7:CD002279.

17 Wong MCM, Clarkson J, Glenny A-M, et al. Cochrane reviews on the benefits/risks of fluoride toothpastes. J Dent Res 2011;90:573-9.

18 ISD Scotland, Childsmile. NHS National Services Scotland. Available: https://www.isdscotland.org/Health-Topics/Dental-Care/ Childsmile/ [Accessed 01 Nov 2020].

19 ISD Scotland. General Dental Service - Registrations and Participation Analysis:. Available: https://www.isdscotland.org/ Health-Topics/Dental-Care/General-Dental-Service/registration-andparticipation.asp [Accessed 01 Nov 2020].

20 ISD Scotland. National Dental Inspection Programme (NDIP) 2019 - Report of the 2019 Detailed Inspection Programme of Primary 7 Children and the Basic Inspection of Primary 1 and Primary 7 children NHS National Services Scotland; 2019. https://ndip. scottishdental.org/wp-content/uploads/2019/10/2019-10-22-NDIPReport.pdf [Accessed 01 Nov 2020].

21 Scottish Government. Overall SIMD 2009 and individual domains. Available: https://www2.gov.scot/Topics/Statistics/SIMD/ Background-Data-2009 [Accessed 01 Nov 2020].

22 Kidd JBR. Developing a population data linkage cohort to investigate the impact on child oral health outcomes following the roll-out of the Childsmile programme in Scotland, 2019. Available: http://theses.gla.ac.uk/76718/1/2019KiddPhD.pdf [Accessed 01 Nov 2020]

23 Kendrick SW, Douglas MM, Gardner D, et al. Best-link matching of Scottish health data sets. Methods Inf Med 1998;37:64-72.

24 Central Evaluation \& Research Team. Childsmile national Headline data, 2015. Available: http://www.child-smile.org.uk/uploads/ documents/5225-Childsmile\%20National\%20Headline\%20Data\% 202015\%2011.pdf [Accessed 01 Nov 2020].

25 ISD Scotland. National dental inspection programme (NDIP) 2015 report of the 2015 detailed national dental inspection programme of primary 7 children and the basic inspection of primary 1 and primary 7 children. Available: https://ndip.scottishdental.org/wp-content/ uploads/2015/10/ndip_scotland2015-P7.pdf [Accessed 01 Nov 2020].

26 Pine CM, Pitts NB, Nugent ZJ. British association for the study of community dentistry (BASCD) guidance on the statistical aspects of training and calibration of examiners for surveys of child denta health. A BASCD coordinated dental epidemiology programme quality standard. Community Dent Health 1997;14 Suppl 1:18-29.

27 ISD Scotland, eDRIS. Public Health Scotland [formerly NHS National Services Scotland]. Available: https://www.isdscotland.org/Productsand-Services/eDRIS/ [Accessed 01 Nov 2020].

28 Benchimol El, Smeeth L, Guttmann A, et al. The reporting of studies conducted using observational Routinely-collected health data (record) statement. PLoS Med 2015;12:e1001885.

29 Gilbert R, Lafferty R, Hagger-Johnson G, et al. Guild: guidance for information about linking data sets. J Public Health 2018;40:191-8.

30 Macpherson LMD, Ball GE, Brewster L, et al. Childsmile: the Nationa child oral health improvement programme in Scotland. Part 1: establishment and development. Br Dent J 2010;209:73-8.

31 Turner S, Brewster L, Kidd J, et al. Childsmile: the National child oral health improvement programme in Scotland. Part 2: monitoring and delivery. Br Dent J 2010;209:79-83.

32 Hodgins F, Sherriff A, Gnich W, et al. The effectiveness of dental health support workers at linking families with primary care dental practices: a population-wide data linkage cohort study. BMC Oral Health 2018;18:191.

33 Duijster D, Verrips GHW, van Loveren C. The role of family functioning in childhood dental caries. Community Dent Oral Epidemiol 2014;42:193-205.

34 Marshman Z, Ahern SM, McEachan RRC, et al. Parents' experiences of toothbrushing with children: a qualitative study. JDR Clin Trans Res 2016;1:122-30. 
35 Lambert MJ, Vanobbergen JSN, Martens LC, et al. Socioeconomic inequalities in caries experience, care level and dental attendance in primary school children in Belgium: a cross-sectional survey. BMJ Open 2017;7:e015042.

36 Nuttall NM, Gilbert A, Morris J. Children's dental anxiety in the United Kingdom in 2003. J Dent 2008;36:857-60.

37 Harris R, Gamboa A, Dailey Y, et al. One-To-One dietary interventions undertaken in a dental setting to change dietary behaviour. Cochrane Database Syst Rev 2012:CD006540.

38 Tickle M, O'Neill C, Donaldson M, et al. A randomized controlled trial of caries prevention in dental practice. J Dent Res 2017;96:741-6.

39 de Sousa FSdeO, Dos Santos APP, Nadanovsky P, et al. Fluoride Varnish and dental caries in preschoolers: a systematic review and meta-analysis. Caries Res 2019;53:502-13.
40 Fleming M, Fitton CA, Steiner MFC, et al. Educational and health outcomes of children treated for type 1 diabetes: ScotlandWide record linkage study of 766,047 children. Diabetes Care 2019;42:1700-7.

41 Public Health Research Data Forum. Enabling data linkage to maximise the value of public health research data: full report. Available: https://wellcome.ac.uk/sites/default/files/enabling-datalinkage-to-maximise-value-of-public-health-research-data-phrdfmar15.pdf [Accessed 01 Nov 2020].

42 Julihn A, Soares FC, Hjern A, et al. Socioeconomic determinants, maternal health, and caries in young children. JDR Clin Trans Res 2018;3:395-404.

43 Bohensky MA, Jolley D, Sundararajan V, et al. Data linkage: a powerful research tool with potential problems. BMC Health Serv Res 2010;10:346. 